\title{
Consciousness-raising in animal welfare through practical experience with horses
}

\author{
Roberto Trentini ${ }^{1}$, Marilena Sticco ${ }^{2}$, Filomena J. Misantone ${ }^{2}$, Umberta Persichetti ${ }^{2}$, \\ Giovanni Gamberini ${ }^{3}$, Nicola Bernabò ${ }^{2}$, Pia Lucidi ${ }^{2 *}$ \\ ${ }^{1}$ Istituto Zooprofilattico dell' Abruzzo e del Molise "G. Caporale”, Teramo, Italy \\ ${ }^{2}$ Department of Comparative Biomedical Science, School of Veterinary Medicine, University of Teramo, Teramo, Italy; \\ *Corresponding Author: plucidi@unite.it \\ ${ }^{3}$ Associazione Ippovie Toscane, Sovicille, Italy
}

Received 17 September 2011; revised 22 October 2011; accepted 3 December 2011

\section{ABSTRACT}

In Italy, Law no. 189/2004 (enforced by law n. 201/2010) on safeguarding animal welfare establishes penalties for anyone keeping animals in conditions that are incompatible with their physiological or ethological needs. Thus, in order to recognize the condition of poor welfare or mistreatment, the training of a veterinarian needs to adopt a new approach to animal well being -that is somewhat different from the health ideas that have been prevalent so far. In this research we carry out an evaluation of the competence of veterinary students after a theoric 20-hour course in ethology and after three weeks of practical horses handling class. For two years 24 students were selected to took part in a program of horse management, in order to reach a high level of practical competence, from the ability to recognize non-verbal signals from horses, to cleaning and grooming, and to a more specific and refined ability-the establishment of a relationship with horse. While the skill level at the beginning was generally low, being the students' backgrounds mainly urban, at the end of the practical course nearly $90 \%$ of them succeeded in the area of horse-human relationship, reaching evaluations in a range of good-excellent scores $(p<0.01)$. By combining over the years the applied ethology knowledge with the more profession-oriented health-related subjects, veterinary education will give students the resources that can better assist them in facing the challenges they will meet in their working lives. The fact that too many unlawful horses' establishments are often found all over the countries point indeed to a need for new experienced, well-trained professional people.
Keywords: Animal Welfare; Applied Ethology; Horse; Veterinary Education

\section{INTRODUCTION}

All over the world, there is so far an unfortunate tendency to underestimate the importance of animal health in relation to animal welfare [1], thus considering the prevention and the control of animal diseases a major contribution to animal welfare [2]. Veterinary schools, mostly devoted to animal health and productivity, have neglected the topic of animal welfare for years in Italy as well. Maybe for these reason the veterinary class, although well qualified in the field of health care, is sometimes less fighting in relation to the last (fourth and fifth) freedoms of the Brambell report

(http://www.fawc.org.uk/freedoms.htm). This is a nonsense, considering that Italy has excellent laws protecting animals - in particular, law no. 189/2004 of the penal code entitled Offences against animal feelings. Apart from the extraordinary importance of the title, which assumes that animals have feelings and are sentient beings, this law is also important because it declares the necessity for animals to be kept in conditions that are "compatible with their specific physiological and ethological needs". For an effective welfare control, this law impliedly suggests the necessity of new prepared professional people in the veterinary class, in order to prevent, advice, and punish every facility where animals' mistreatment conditions and poor welfare subsist.

One of the aspects required to understand the animals' welfare condition is the knowledge of their perceptual world and behavior. However, this knowledge can only improve if students are trained through practical experience "in the flesh" and not with just theoretical studies. In regard to this, ethology classes could properly introduce to the animals' body language, which reveals the animals' psychophysical state, according to the satisfac- 
tion of their physiological needs. Differently from clinical practice, where the presence of animals could be bypassed with alternative models, mannequins, and technological tools [3], ethology class can efficiently afford the human-animal ethical relationship by the practical handling of healthy animals. In this way, it could allow to integrate the medical-based knowledge with that of the animals' management, which is as important as diseases control for the animal welfare assessment.

Why horses? Because, among the students enrolled in the courses at Veterinary School of Teramo, the majority own cats, dogs or rabbits, while very few have any familiarity with horses (Lucidi, unpublished data). The small percentage who claim a knowledge of horses tend to belong to riding schools, where their attitude towards the animals is conditioned by the time they spend with them, always too short and poor. Often the horses leave the stall only to be ridden, and frequently their grooming and welfare are totally neglected by the owners: the average owner (student) believe that keeping a horse in a riding stall, is a "normal" condition of life for the animal. None of the students questioned in the last 10 years has ever thought that keeping horses in a stall, in other words making them "live" in a stall, is like believing cats living their entire life in a cat-carrier.

Because of this poor knowledge and lack of relationship, it often happens that the animal's communication signals are largely misunderstood and horses are ranked as sour, unresponsive or dangerous, and undeservedly punished. So, the fact that horses are less popular pets than others animals and that their non-verbal communication signals are mostly unknown, prevents today's students (and tomorrow's vets) from turning a critical eye on in evaluating horses condition and welfare.

This longitudinal research took into consideration the consciousness-raising of students towards horse welfare by means of a course of ethological horse management that give them the basic knowledge of how to practically and safely approach and deal with horses. The reason for this choice resided in the fact that 1) the horse is an animal that students come across "in the flesh" at the end of their studies, when we know their empathy towards animals' suffering can decline [4]; 2) in order to become veterinarians that can effectively ensure the welfare of the animals committed to their care, they should not only understand the theoretical veterinary background, but also have "hands-on" knowledge [5,6]. The horse management program was introduced at the end of the first year, after the students had learnt the basic foundation of anatomy, zoognostic and ethology. Preclinical years seem indeed to be the more appropriate time to cover the basic principles and methodologies of welfare science [7]: if the students could acquire such precocious knowledge, their comprehension of animal signals would greatly improve and they would certainly be a superior graduate, bridging the gap between what studied in the textbook and what the real practice should be [8].

\section{MATERIALS AND METHODS}

Twenty-four volunteer students were selected on the basis of their low practical knowledge of horses (Table 1) and provided with tools for practical horse care: horse brushes, curry combs, hoof picks, lead ropes, harnesses, shovels, wheelbarrows, pitchforks, etc.

The students admitted to the program handled eleven horses in total; apart from two animals looked after by three students, all the others were in the care of pairs of students. The horses were of different origins and ages, as follows: 5 (geldings) were permanently stabled in the School; the others were animals who were brought in for artificial insemination or other reason (board). The breeds, in the first and second years of the program, were Quarter horses, Italian saddle-horses, and English thoroughbreds. On the first day the students compiled a register (Figure 1) on their allocated horse, in which they noted various information: horse's name, breed, date of birth, body markings, previous health details, particular individual behavior (these last provided by the caretaker).

The students practiced horse care for three weeks, filling the animal-student activities' report (Figure 2 and 3) with the aim of learning the basics of animal management as well as encouraging the human-animal bond by improving their knowledge of horses' body language. Each week ran from Monday to Friday, and the students worked early in the morning, from 7.30 to 10.30 . Tutors (the authors, with the exception of GG) were present to

Table 1. Students' background assessment.

\begin{tabular}{|c|c|c|c|c|}
\hline Items & Theoric & knowledge & Practical & nowledge \\
\hline horse's morphology & yes & no & yes & no \\
\hline horse's breed and sex & yes & no & yes & no \\
\hline horse's gaits & yes & no & yes & no \\
\hline tail posture & yes & no & yes & no \\
\hline ears posture & yes & no & yes & no \\
\hline fearful/relaxed & yes & no & yes & no \\
\hline friendly/aggressive & yes & no & yes & no \\
\hline grooming/bite & yes & no & yes & no \\
\hline equipment identification & yes & no & yes & no \\
\hline equipment use & yes & no & yes & no \\
\hline
\end{tabular}

Students knowledge was investigated by asking them to recognize some morphological and behavioral traits of the horses that they should have gained throughout different $1^{\text {st }}$ year lessons (anatomy, ethology, ethnology). The last two items were included as a measure of students' familiarity with horse management and care. The equipment used for this final test were: brushes, curry combs, hoof picks, combs, sweat scraper, saddle, bridle etc. The students were accepted when their practical knowledge contained five or more "no" score in the items. 
ANIMAL REGISTER

NAME

BREED

COAT

AGE OR DAY OF BIRTH

OWNER

DISTINCTIVE FEATURES

ANY PREVIOUS DISEASE

TREATMENTS

Figure 1. Animal's signaling.
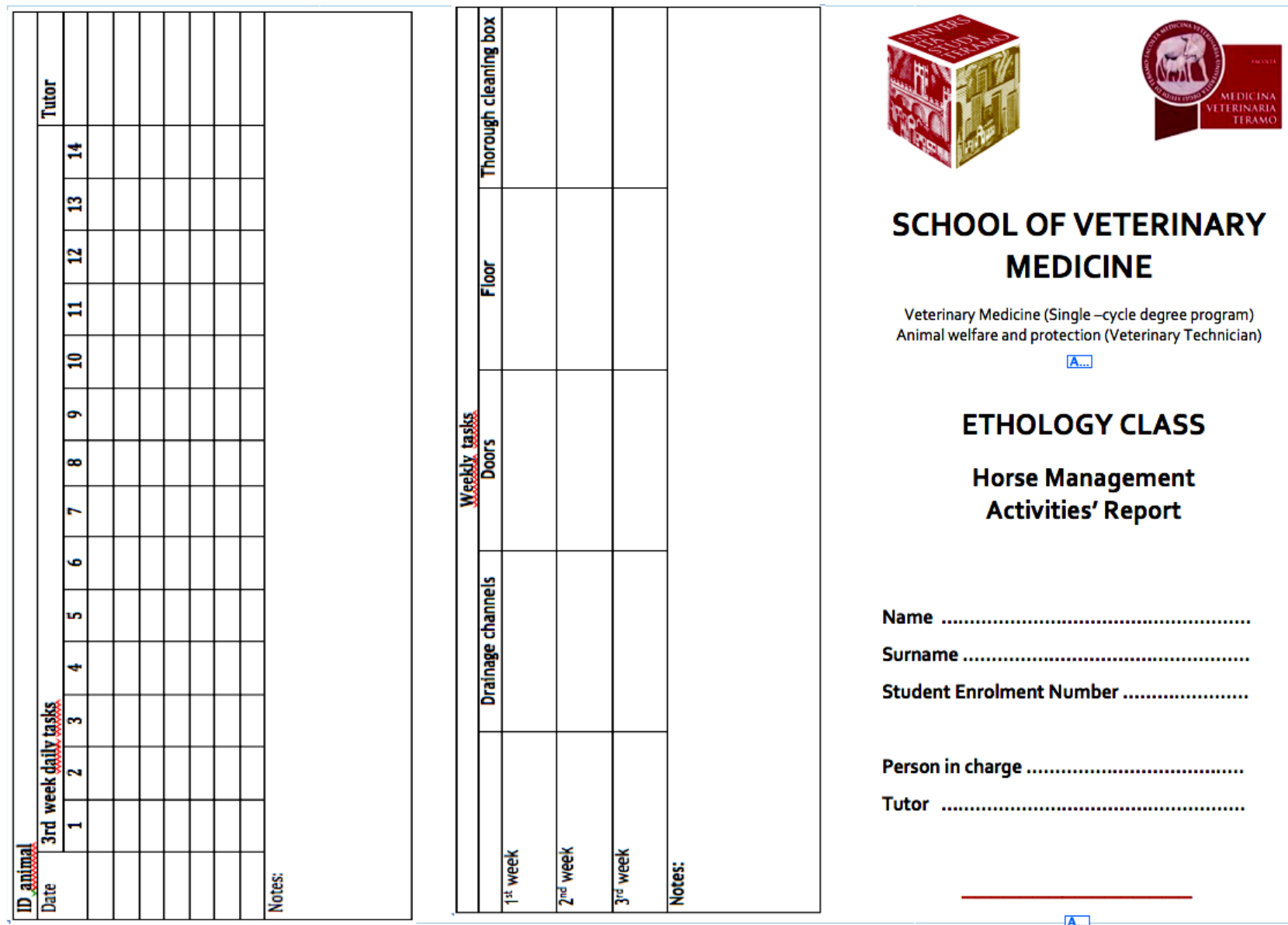

SCHOOL OF VETERINARY MEDICINE

Veterinary Medicine (Single -cycle degree program) Animal welfare and protection (Veterinary Technician) A...

\section{ETHOLOGY CLASS}

Horse Management

Activities' Report

Name

Surname

Student Enrolment Number

Person in charge

Tutor

A...

Figure 2. Horse management activities' report, external sheet. 


\section{First day:}

Filling of the chosen animal's individual register.

\section{Daily tasks:}

1) Cleaning the box of faeces and urine, and laying down a new floor bedding

2) Checking and cleaning the drinking trough

3) Supplying feed and fresh water

4) Cleaning the horse with brush, curry comb and hoof pick

5) Massage

6) Passive stretching of neck and back

7) Habituation to bit, longe, crop, games (ball)

8) Saddling/desaddling

9) Leading the horse into the paddock

10) Observing the horse in the paddock

11) Leading the horse back to its box

12) Cleaning the horse (coat, tuft, hooves)

13) Giving the horse food and fresh water

14) Measuring physical parameters (heart rate, breathing, temperature)

\section{Weekly tasks:}

1) Check of the drainage channels

2) Check of the doors

3) Check of the floors

4) Thorough cleaning of the box (removing cobwebs, etc.)

A...

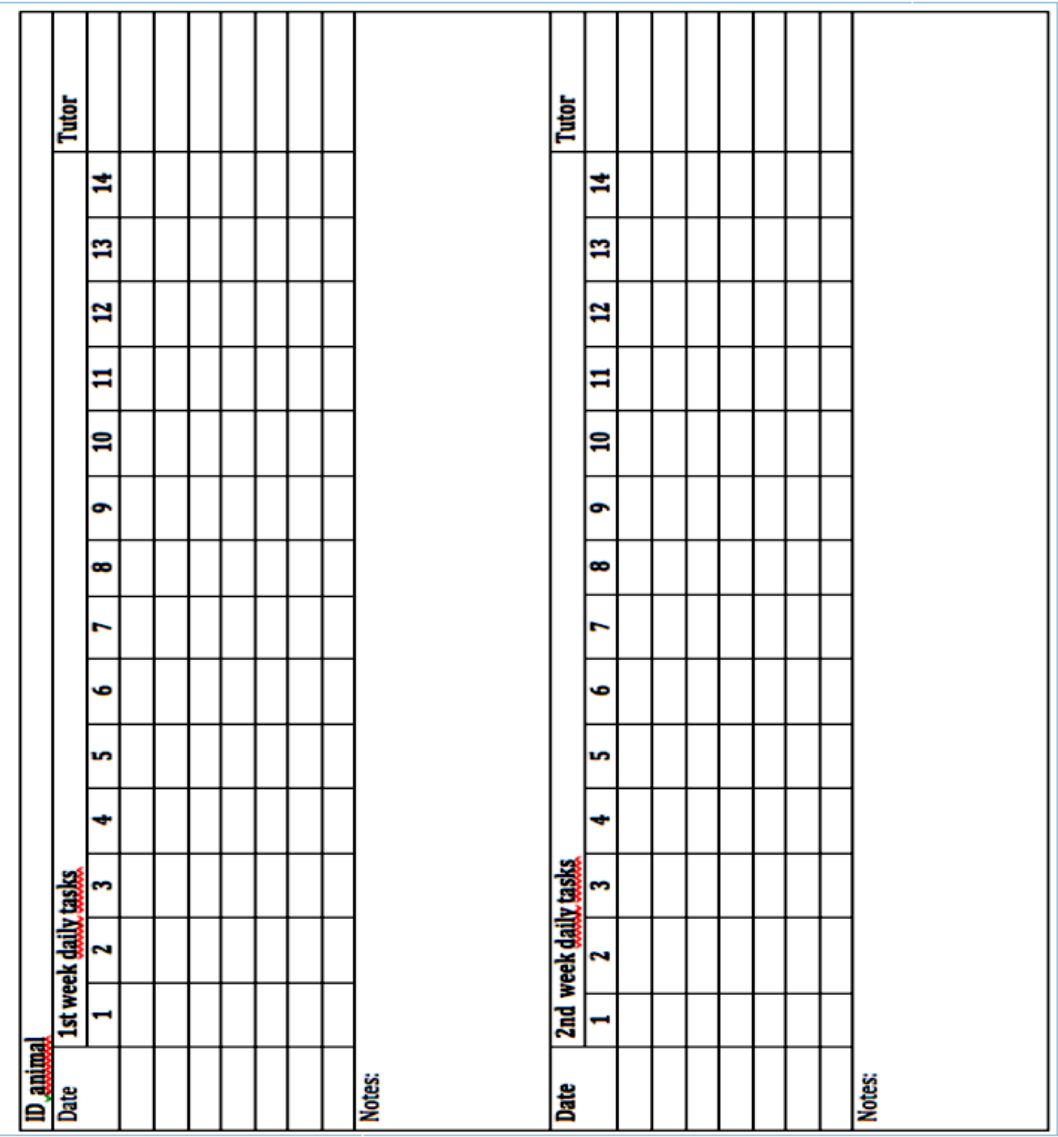

Figure 3. Horse management activities' report, inside sheet.

check the students' work, and give suggestions on problems encountered, and closely supervised to correct any wrong practices. The experiment was repeated the following year, with 24 new students working on 11 horses.

As set out in the horse management chart (Figure 3), the students had to carry out 14 tasks every day, following a checklist. The correct saddling of the horse (Figure 3 , item no. 8) was dropped from subsequent programs due to economic reasons. Apart from these daily tasks, at the end of the week the students had to check the drainage channels, the doors, the floors and carry out a thorough cleaning of the box-stall, removing cobwebs and other dirt (on the walls, the ceiling, etc.) which was not done in the daily cleaning routine. Any observations were duly noted in the register.

At the end of each week, the students were assessed (by GG) according to their performance in three separate skills:

- Skill no. 1: the ability to recognize in the field horses' behaviors based on the knowledge acquired in theoric lessons, as regards ethology and the psycho-biological basis of animal perception. The horses' behaviors were not "elicited" at the moment: the student was asked to recognize all the behaviors showed by their animal during the daily traffic of conspecific and humans in the structure.

- Skill no. 2: involved all the practices included in the horse care sheet-practical and management skills, how to approach the horse, how to touch it, how to correctly fit a halter and a longe, how to lead the horse safely to the paddock, etc. (Figure 3-5).

- Skill no. 3: this was considered to be the most advanced skill - a relationship with the horse. Each student had to demonstrate to have formed a relationship with the assigned horse, by managing the animal in the arena, together with other free horses (carrying out the daily tasks in the field). This skill required, indeed, a good relationship with horses in order to safely handle them in this new situation.

The final marks for each skill were: 0 , extremely poor; 1 , poor; 2 , adequate; 3 , good; 4 , excellent.

\section{DATA ANALYSIS}

The Shapiro-Wilks W Test was used to check data conformation to normal distribution; data on the average scores for each separate week was compared using ANOVA for repeated measurements, followed, where neces- 


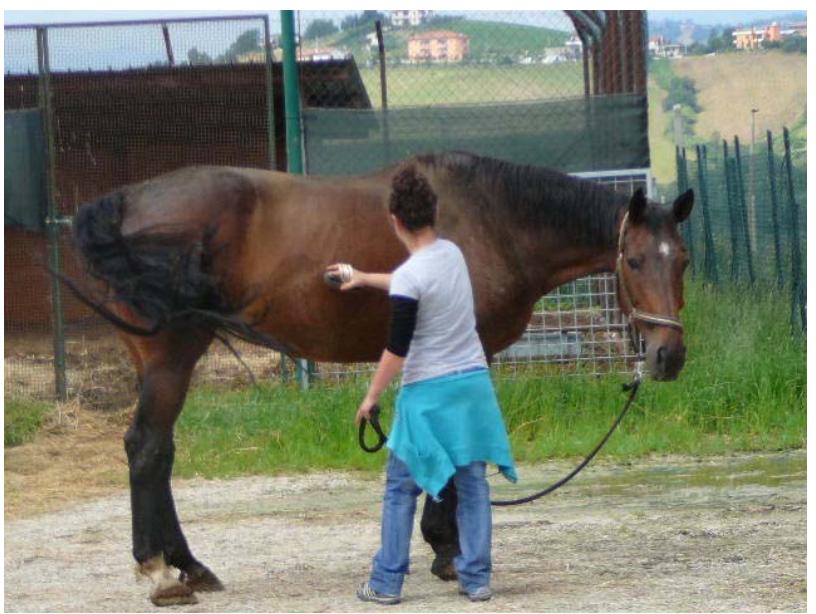

Figure 4. Grooming of horse.

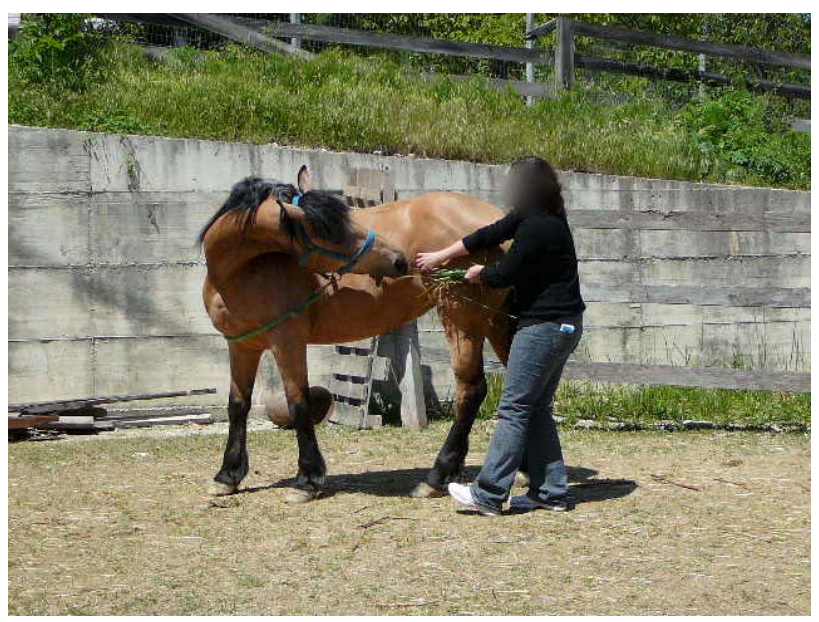

Figure 5: Stretching of horse's neck.

sary, by a Tukey test.

\section{RESULTS}

As shown in Table 2, in both years the students started out on average at a poor level of performance for all the skills tested. The "time zero" (the start of the course) in fact, apart from the mean values of skill no. 3 in the first year $(1.033 \pm 0.923)$, showed values constantly below two (from poor to adequate). There were no observable differences between the different years for any of the skills $(\mathrm{p}>0.05)$.

On the other hand, for all the years and for all the skills, there was an increasingly higher performance over time. At the end of the three weeks of the course the values became definitely adequate, and between the beginning of the course (T0) and the end (T3) there was a constant difference of $\mathrm{p}<0.01$. Students' shyness towards horses was always replaced by confidence, trust, and respect, even when a horse was not properly well-disposed or actually biting, as in the case of Angela: her allocated horse, known as Hannibal for his habit to bite, greatly improved his behavior after a week, redirecting his nasty habit on a ball (data not shown).

\section{DISCUSSION}

Statistical evidence suggests that students enrolled in Italian Veterinary School are more and more female (67.1\%), belonging to every class (lower, upper, middle class), mainly from senior high school specializing in science education

(http://www2.almalaurea.it/cgi-php/universita/statistiche/ ); in our University, which is in central Italy, they come mainly from urban environment, too often unaware of animals' communication signals, although their declared "feelings" towards animals (official data from the School secretariat).

At Teramo Veterinary School anyway, few subjects address the topic of animal-human bond in any practical way, and when they do it, more attention is given to cats, dogs and some exotic animals kept as pets. Horses, which are less "companionable" than dogs or cats (low self experience) and less practiced (low class experience), are animals that Veterinary students are acquainted with only through the theoretical studies carried out in different disciplines. Therefore, if the first practical encounter with an animal of this size takes place during profession-oriented classes (the last two years), this can makes

Table 2. Students' performance.

\begin{tabular}{ccccc}
\hline Skills & PERIOD & T0 & T1 & T2 \\
\hline \multirow{2}{*}{ skill 1 } & $1^{\text {st }}$ year & $0.934 \pm 0.898$ & $1.345 \pm 0.895$ & $2.215 \pm 0.978$ \\
& $2^{\text {nd }}$ year & $0.923 \pm 0.934$ & $1.234 \pm 0.789$ & $2.345 \pm 0.894$ \\
\multirow{2}{*}{ skill 2 } & $1^{\text {st }}$ year & $0.654 \pm 0.567$ & $0.832 \pm 0.657$ & $1.305 \pm 0.878$ \\
& $2^{\text {nd }}$ year & $0.599 \pm 0.768$ & $0.635 \pm 0.956$ & $1.357 \pm 0.765$ \\
skill 3 & $1^{\text {st }}$ year & $1.033 \pm 0.923$ & $0.456 \pm 0.905$ & $0.612 \pm 0.991$ \\
& $2^{\text {nd }}$ year & $0.530 \pm 0.934$ & $0.678 \pm 0.956$ & $2,477 \pm 0.644$ \\
\hline
\end{tabular}

Competences acquired in different skills by students during three weeks of a "horse management program". T0: time zero; T1, T2, T3 are respectively the average evaluation of $1^{\text {st }}, 2^{\text {nd }}$, and $3^{\text {rd }}$ week \pm standard deviation. Evaluation scores were: $0=$ extremely poor; $1=$ poor; $2=$ adequate; $3=$ good; $4=$ excellent. Although no differences were recorded between the students from the $1^{\text {st }}$ and $2^{\text {nd }}$ year, there was a constant and significant difference between $\mathrm{T} 0$ and $\mathrm{T} 3 \mathrm{for}$ all the skills tested $(\mathrm{p}<0.01)$. 
students apprehensive or frightened, running the risk of being injured [9] or confusing the signs of poor welfare with those of a bad temperament.

Even more often, the horse-human relationship cannot be taken in consideration by clinicians: in fact, they need much more time to focus on the health aspects and diagnostic pathology, and the amount of topics and the shortage of time does not allow them to approach horses in natural conditions. If authoritative sources advocate that a veterinarian dealing with horses should make an effort to acquire basic riding experience in order to prevent poor welfare such as rollkur [5], likewise the knowledge of all the aspects of stable management is of extreme importance, alongside the horses' physiological and ethological needs. For example, a horse's stall can tell people something of the horse who lives in it, how he/she has passed the night, if he/she is well looked after or not, if he/she shows "bad stable habits", and so on, but this is only visible to someone who can see with a careful, trained eye. The horses that a student can observe in the clinic environment are often just patients, maybe in emergency, not the energetic, free horses we propose to students during the lessons of Ethology.

In this study the skill level of the students at the beginning was generally low: most of them had never had a direct contact with horses, being their backgrounds mainly urban. The students were selected for their low experience of horses: in fact, most of them had no idea of how to transfer their theoretical basis to the practical aspects of management. Few among them owned horses or had some acquaintance with them from riding schools, and it is their experience the responsible for the variations at $\mathrm{T} 0$, for example in skill no. 1. As days passed, however, the ability to understand the behavior patterns of horses reached an adequate level, and the students rapidly began managing the animals in a more competent fashion until they reached the level of skill no. 2 .

An important point is that skills 2 and 3 require a series of competences, which the practical course succeeded in giving the students; in fact, those students who had had access to other sources of information did not start out with any particular advantage. Moreover, since the results were substantially similar over the two years, we can infer that the results obtained are not year-specific but conclusive in an absolute sense.

This demonstrates that while other (preparatory) courses "prepare" to any practical work involved, the practical aspect is necessary for a qualitative leap; the animal handling class, indeed, allows the students to reach levels of skill that they could not acquire by any other means. Although early evaluation showed better results for skills 1 and 2 compared to skill 3 , at the end of the course the scores achieved were more than adequate for all the three skills. The last achievement, i.e. the im- provement in skill no.3, although it was only visible after improvement in the level of the other two skills, represents an important goal; it does involve the ability to communicate with a horse at a higher level than in the skills 1 and 2.

We can therefore state that the practical course in ethological horse handling and management, as well as being greatly appreciated by the students, achieved its declared objective: the raising of students' consciousness towards the comprehension of horses' body language, prerequisite for a satisfactory human-animal bond and, consequently, towards appraising animal welfare, using an animal that they are less acquainted with. The scores obtained at the end of the courses are substantially different from those at the beginning, indicating that there was real learning by the students. The four steps seems to be sufficient to reach the target: it is noteworthy that, as time goes by, the results obtained by the students improved in every case; thus, the practical animal handling turns out to be indispensable, and most likely, such results would not have been possible in its absence.

Lengthening the period of ethological horse management in order to improve the performance in skill 3 would probably have increased the number of adequate values, but this would have led to insurmountable organizational obstacles. In our experiment, we moved from around $15 \%$ to $25 \%$ of able students after one week to around $80 \%$ to $90 \%$ at the end of the course. However, only in the case of skill 2, did previous experience of horses influence the final outcome $(r=0.626$ for the first year and $\mathrm{r}=0.715$ for the second, $\mathrm{p}<0.01$ ), while for the other skills there was no correlation between previous background and the values relative to horse management practice. This appears to confirm that a cultural and scientific approach contributed by university studies is necessary; in other words, the knowledge acquired during the project by mere exposure to the animal would not have been in itself sufficient or useful.

\section{CONCLUSIONS}

The pressing demand to qualify vets in the field of welfare $[10,11]$ together with the need to gain new skills in animal practice, suggests training the students more incisively to zoo-anthropology and ethological animal handling. This is absolutely true when students come from urban environments, unaware of the animals' communication signals or physiological requirements, particularly for horses.

The students' theoretical background could be notably consolidated by daily practical experience with horses, and a high standard of horsemanship could be obtained, which would be important not only for the student's education but also for the horses' welfare. 
As stated by Martinsen and Jukes [6], the work with living animals is essential: the animals themselves should always benefit from such experience, or at least not be harmed. In agreement with this statement, we strongly believe that the observation of natural behavior as well as the handling of healthy animals can be a powerful tool to put the basis for a human veterinary education.

Teachers should always spur their students toward the analysis of animals in their context, through their relationship with humans and the environment in which they live, as wished by Fox more than forty years ago [12] and as expected by the social pressure not only for pets but even more for farm animals [13,14].

It is desirable that the practical and ethical animalhandling classes could become a must in all Veterinary School in Italy, and hopefully follow the experience of other countries, where second-year students cannot progress until they have achieved the required competence to handle animals in a safe, ethical, competent way [15].

\section{ACKNOWLEDGEMENTS}

The Authors thank Prof. Francesca Rosati (University of Teramo) for the editing of this paper. The study was financed by the $60 \%$-Research Program-Year 2009, University of Teramo.

\section{REFERENCES}

[1] Millman, S.T., Adams, C.L. and Turner, P.V. (2005) Animal welfare training at the Ontario veterinary college. Journal of Veterinary Medical Education, 32, 447-450. doi:10.3138/jvme.32.4.447

[2] Bayvel, A.C. and Cross, N. (2010) Animal welfare: A complex domestic and international public-policy issueWho are the key players? Journal of Veterinary Medical Education, 37, 3-12. doi:10.3138/jvme.37.1.3

[3] Abutarbush, A.M., Naylor, J.M., Parchoma, G., D’Eon, M., Petrie, L. and Carruthers, T. (2006) Evaluation of traditional instruction versus a self-learning computer module in teaching veterinary students how to pass a nasogas- tric tube in the horse. Journal of Veterinary Medical Education, 33, 447-454. doi:10.3138/jvme.33.3.447

[4] Paul, E.S. and Podberscek, A.L. (2000) Veterinary education and students' attitudes towards animal welfare. Veterinary Record, 4, 269-272. doi:10.1136/vr.146.10.269

[5] Heuschmann, G. (2007) Finger in der wunde. I. Sonntag Ed., Wu Wey Verlag., Shondorf am Ammersee, Germany.

[6] Martinsen, S. and Jukes, N. (2005) Towards a humane veterinary education. Journal of Veterinary Medical Education, 32, 454-460. doi:10.3138/jvme.32.4.454

[7] Main, D.C.J. (2010) Evolution of animal-welfare education for veterinary students. Journal of Veterinary Medical Education, 37, 30-35. doi:10.3138/jvme.37.1.30

[8] Klinghammer, E. and Fox, W. (1971) Ethology and its place in animal science. Journal of Animal Science, 32, 1278-1283.

[9] Hausberger, M., Roche, H., Henry, S. and Visser, E.K. (2008) A review of the human-horse relationship. Applied Animal Behaviour Science, 109, 1-24. doi:10.1016/j.applanim.2007.04.015

[10] Advice of the last World Conference on Veterinary Education, France 2011.

[11] Levine, E.D., Mills, D.S. and Houpt, K.A. (2005) Attitudes of veterinary students at one US college toward factor relating to farm animal welfare. Journal of Veterinary Medical Education, 32, 481-490. doi:10.3138/jvme.32.4.481

[12] Fox, W. (1967) The place and future of animal behavior studies in veterinary medicine. Journal of the American Veterinary Medical association, 151, 609-615.

[13] Gregory, N.G. and Grandin, T. (2007) Animal welfare and the meat market. In: Gregory, Ed., Animal Welfare and Meat Production, 2nd Edition, CABI, Oxforshire, 1-21.

[14] Horgan, R. and Gavinelli, A. (2006) The expanding role of animal welfare within EU legislation and beyond. Livestock Science, 103, 303-307. doi:10.1016/j.livsci.2006.05.019

[15] Hanlon, A., Gath, V. and Mulligan, F. (2007) Practical animal-handling classes at university college Dublin. Journal of Veterinary Medical Education, 34, 561-565. doi:10.3138/jvme.34.5.561 